Article

\title{
An Improved Algorithm for Discriminating Soil Freezing and Thawing Using AMSR-E and AMSR2 Soil Moisture Products
}

\author{
Huiran Gao ${ }^{1,2} \mathbb{D}$, Wanchang Zhang ${ }^{1, *}$ and Hao Chen ${ }^{1,2} \mathbb{D}$ \\ 1 Key Laboratory of Digital Earth Science, Institute of Remote Sensing and Digital Earth, Chinese Academy of \\ Sciences, Beijing 100094, China; gaohr@radi.ac.cn (H.G.); chenhao01@radi.ac.cn (H.C.) \\ 2 University of Chinese Academy of Sciences, Beijing 100049, China \\ * Correspondence: zhangwc@radi.ac.cn; Tel.: +86-10-8217-8131
}

Received: 4 September 2018; Accepted: 25 October 2018; Published: 27 October 2018

check for updates

\begin{abstract}
Discriminating between surface soil freeze/thaw states with the use of passive microwave brightness temperature has been an effective approach so far. However, soil moisture has a direct impact on the brightness temperature of passive microwave remote sensing, which may result in uncertainties in the widely used dual-index algorithm (DIA). In this study, an improved algorithm is proposed to identify the surface soil freeze/thaw states based on the original DIA in association with the AMSR-E and AMSR2 soil moisture products to avoid the impact of soil moisture on the brightness temperature derived from passive microwave remotely-sensed soil moisture products. The local variance of soil moisture (LVSM) with a 25-day interval was introduced into this algorithm as an effective indicator for selecting a threshold to update and modify the original DIA to identify surface soil freeze/thaw states. The improved algorithm was validated against in-situ observations of the Soil Moisture/Temperature Monitoring Network (SMTMN). The results suggest that the temporal and spatial variation characteristics of LVSM can significantly discriminate between surface soil freeze/thaw states. The overall discrimination accuracy of the improved algorithm was approximately $89 \%$ over a remote area near the town of Naqu on the East-Central Tibetan Plateau, which demonstrated an obvious improvement compared with the accuracy of $82 \%$ derived with the original DIA. More importantly, the correct classification rate for the modified pixels was over $96 \%$.
\end{abstract}

Keywords: soil freeze/thaw states; AMSR-E and AMSR2; soil moisture; dual-index algorithm

\section{Introduction}

Seasonal change of surface soil freeze/thaw states is one of the most crucial characteristics of the land surface in higher latitudes, which is closely related to hydrological and ecological processes as well as climatic changes [1-4]. It has a far-reaching impact not only on surface runoff and plant growth but also on energy exchange and water balance $[5,6]$. With global climate change, the corresponding changes in soil freezing and thawing will have a significant influence on the regional environment and ecosystems [7-9].

Traditionally, the spatiotemporal behavior of soil freezing and thawing has been monitored via a limited number of station records, which cannot satisfy the need for conducting comprehensive studies. Satellite remote sensing, especially the development of microwave remote sensing technology provides a valid measure for ground surface observations over large areas [10]. Earth observation with remote sensing on the frozen ground is also one of the critical objectives of the scientific plan of the Earth Observing System (EOS). The potential of remote sensing in the study of surface soil freeze/thaw states has been a major area of interest. 
Passive microwave remote sensing is not influenced by atmospheric conditions and cloud cover [11]. Passive microwaves can obtain information within a certain depth. Moreover, the microwave is very sensitive to the variability of the soil moisture content; fewer microwaves are emitted when soil moisture becomes higher and vice versa. Consequently, surface soil freeze/thaw states could be detected by the characteristics of the microwave emissivity, which contains significant information regarding the dielectric differences between frozen and thawed soils [12-15]. Objects with different temperatures, compositions, and structures emit different microwave radiation energies [11]. The dielectric properties of water and ice differ significantly, which makes it possible to monitor surface freezing and thawing processes using microwave technology [16]. Brightness temperature data, obtained by passive microwave radiometer, has been successfully applied in some cases to discriminate surface soil freeze/thaw states $[5,17,18]$. With the new generation of passive microwave radiometers on board the EOS satellite, passive microwave remote sensing of freezing soils has become an interesting topic for many researchers $[19,20]$. Additionally, high revisit frequency of passive microwave remote-sensing satellites and their ability to provide data with multiple scales has satisfied the high demand of the long-term ground surface freeze/thaw data series for the study of the relationship between the cryosphere and climate change.

Zuemdorfer et al. (1989) found that the negative spectral gradient of the brightness temperature is a good indication of frozen soils. England (1990) revealed that brightness temperature is particularly sensitive to the liquid water content in the soil surface and the scattering effect of frozen soils. Frozen soils have considerably different physical characteristics compared with thawed soils, such as low physical temperature, high emissivity, and low brightness temperature [21]. As the ground-based radiometer measurement suggests [22], the emissivity and the brightness temperature of soils vary in dry and wet states. However, wet soils will have higher emissivity and higher brightness temperatures in the frozen state. Therefore, it can be deduced that changes in radio-brightness are heavily dependent on the soil moisture. However, variations of soil moisture content might result in uncertainty when using the brightness temperature for the discrimination of surface soil freeze/thaw states [23]. For this reason, we attempted to improve the previous discrimination algorithm by taking the soil moisture effect into account.

Several microwave radiometry satellites, i.e., SSM/I (Special Sensor Microwave/Imagery, 1987), AMSR-E (Advanced Microwave Scanning Radiometer-EOS, 2002) and AMSR2 (The second Advance Microwave Scanning Radiometer, 2012), have been launched after the SMMR (Scanning Multichannel Microwave Radiometer) in 1978. Having a long-term microwave data series, accumulated approximately over 40 years, these microwave radiometry satellites provide a unique chance for the study of the temporal and spatial variations of freeze/thaw cycles under the background of global climate changes. Many theories and research experiments are available for monitoring and discriminating ground surface freeze/thaw states by using passive microwave data. Among the few algorithms proposed, the dual-index algorithm (DIA) has been widely used with a $37 \mathrm{GHz}$ vertically polarized brightness temperature (Tb37v) and negative spectral gradient (SG) between $37 \mathrm{GHz}$ and $19 \mathrm{GHz}[2,5,6,21,24]$. The $37 \mathrm{GHz}$ vertically polarized brightness temperature was selected because of its comparative sensitivity to the near-surface temperature. However, limited soil moisture information can be obtained from Tb37v and SG indices, and the spectral gradient of shallow frozen soils could be positive due to weak scattering which might introduce bias into the results $[24,25]$. The decision tree algorithm proposed by Jin et al. (2009) by using three indices (the scattering index, the $37 \mathrm{GHz}$ vertically polarized brightness temperature and the $19 \mathrm{GHz}$ polarization difference) to describe the uncertainty in the discrimination of ground surface freeze/thaw states [26]. In this algorithm, the influence of soil moisture variations has not been considered, leading to the development of a discriminant function algorithm $[27,28]$, seasonal threshold methods [15,29,30], a standard deviation method [20], and a polarization ratio-based algorithm [31-33] to address the issue. However, to our knowledge, only a few studies have investigated the impact of soil moisture on surface soil freeze/thaw states. 
In recent decades, a variety of microwave soil moisture products have been made available in several parts of the world [34-37]. Release and application of the above-mentioned soil moisture products have made it possible to take full account of the spatial and temporal variations of soil moisture content in the discrimination of freeze/thaw states of the ground surface.

In the present study, an improved algorithm based on the DIA was proposed to include the influence of soil moisture variations when using microwave data products for the discrimination of surface soil freeze/thaw states. The improved algorithm was verified against the measurements acquired from the Soil Moisture/Temperature Monitoring Network (SMTMN), and, finally, was applied to the whole territory of China for demonstrating its feasibility.

\section{Materials and Methods}

\subsection{Methodology}

As the most widely used algorithm that only requires two parameters ( $\mathrm{Tb} 37 \mathrm{v}$ and SG) for the discrimination of the frozen and thawed ground surfaces [3,21], the DIA was selected as the fundamental approach in this study. We attempted to improve the discrimination performance of the DIA by taking the effect of soil moisture into account. For this purpose, we analyzed the temporal variations of soil moisture derived from AMSR-E and AMSR2 products to enhance the performance of the DIA. Algorithms used for extracting characteristics of soil moisture from ground-based measurements or satellite products were referenced from Gonzalez and Woods, (1992), Ajafernandez et al. (2006), and Wang (2008) [38-40]. Figure 1 illustrated the framework of the improved algorithm. The implementation of the proposed approach will be presented with a case study in the following sections.

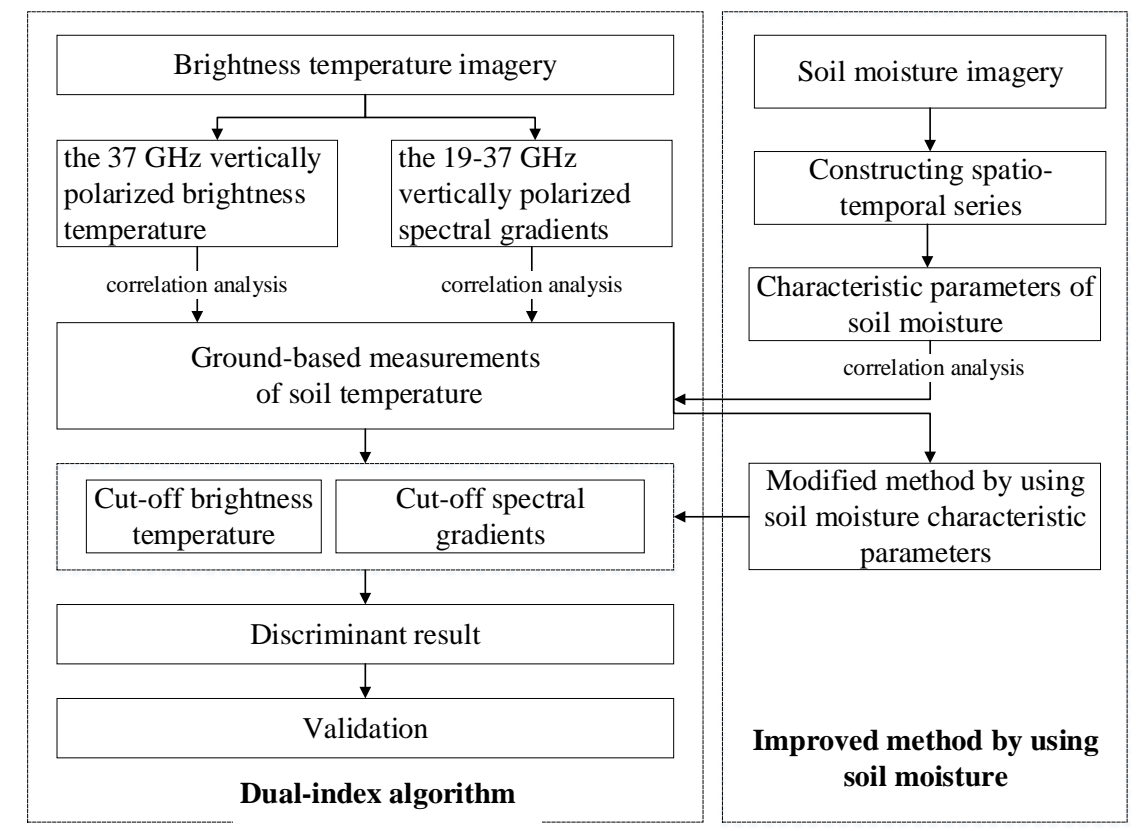

Figure 1. The overall framework of the improved algorithm proposed in this study.

\subsection{Materials}

\subsubsection{Ground-Based Measurements}

In the present study, we selected a remote area near the town of Naqu on the East-Central Tibetan Plateau as an experiment site. Here, there is a multi-scale and densely settled ground-based Soil Moisture/Temperature Monitoring Network (SMTMN) which helped us to develop and validate the improved algorithm. As the highest plateau in the world, covered by seasonal frozen or permafrost 
with an area of about $2.5 \times 10^{6} \mathrm{~km}^{2}$ above an average elevation of $4000 \mathrm{~m}$ a. s. 1., the Tibetan Plateau has been the focus of numerous studies related to monitoring soil freeze/thaw states using remote sensing [26-28].

Ground-based observation data sets of soil moisture and temperature were obtained by ECH2O EC-TM electromagnetic sensors. Temporal coverage of the SMTMN was from 1st August 2010 to 31st July 2014. The soil moisture data of the SMTMN were calibrated with measured di-electricity according to the soil texture and soil organic carbon content; the temperature data used are observed in-situ and processed with quality control. The SMTMN covers a total number of 56 stations distributed over 4470 to $4950 \mathrm{~m}$ a.s.l., and provided data for three spatial scales $\left(1.0^{\circ}, 0.3^{\circ}, 0.1^{\circ}\right.$ gridded $)$ at four soil depths $(0 \sim 5,10,20$, and $40 \mathrm{~cm})$ [41,42]. The experimental area is characterized by low biomass, high soil moisture variations, and typical seasonal freeze/thaw cycles in high elevations.

The $1.0^{\circ}$ gridded ground-based measurements of soil temperature and moisture content from 1st August 2010 to 31st July 2011 and from 1st August 2012 to 31st July 2014 at a depth of $0 \sim 5 \mathrm{~cm}$ were selected to ensure the data availability and synchronicity of the experiment. The selected depth $(5 \mathrm{~cm})$ is approximately equivalent to the depth of microwave observations. As shown in Figure 2, the stations were divided into 20 blocks to match the corresponding AMSR-E and AMSR2 pixels. Only one station from several distributed stations in each of the blocks was selected to match the gridded microwave products, then the values of all the stations in the given pixel were averaged and substituted for the value of the selected station. In total, 12 retained stations were chosen for the purpose, as illustrated in Figure 2.

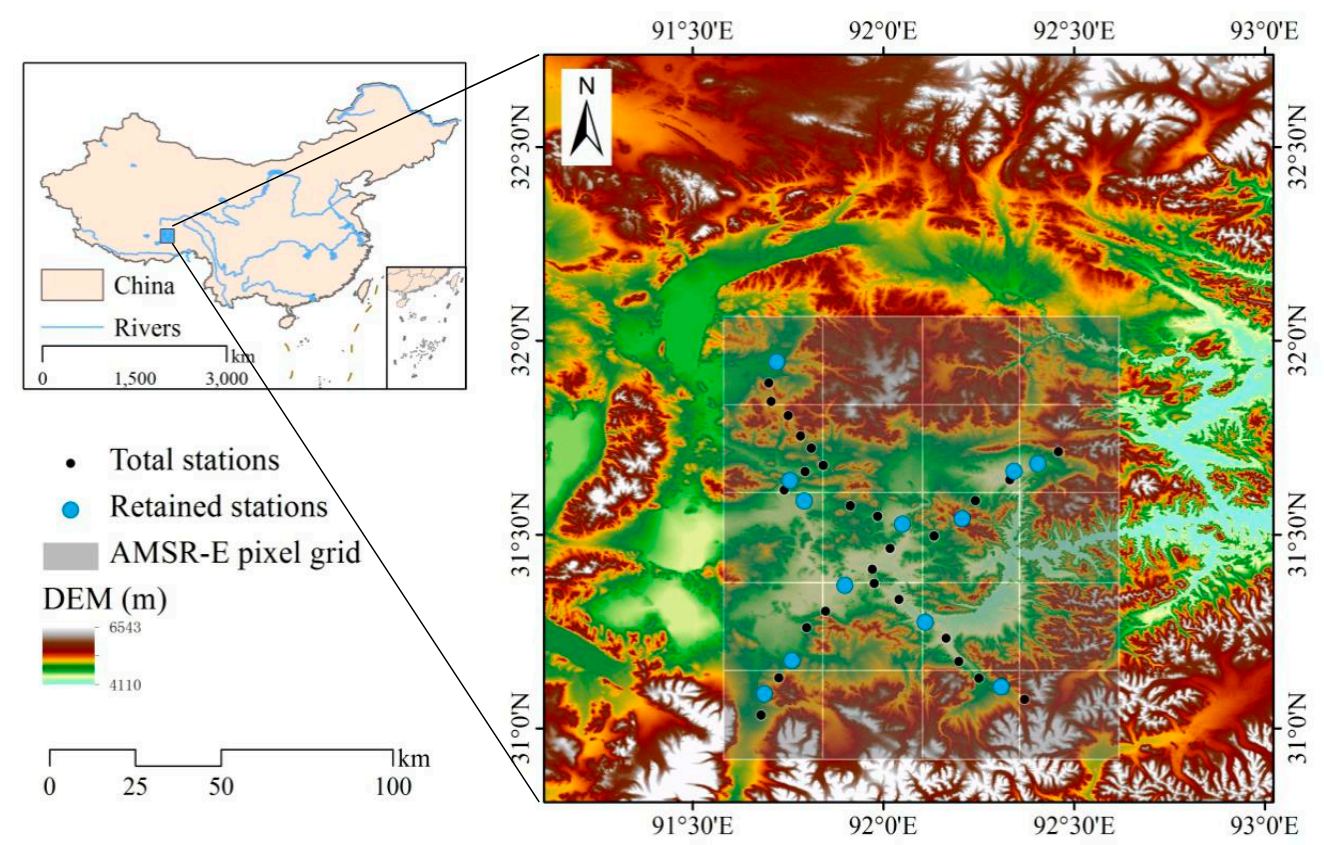

Figure 2. The geographic location of the study area with an overview of the Soil Moisture/Temperature Monitoring Network with $1.0^{\circ}$ gridded blocks.

\subsubsection{Datasets of Microwave Satellite Products}

The National Aeronautics and Space Administration (NASA) AMSR-E daily level-3 land surface soil moisture products in the Equal-Area Scalable Earth Grid (EASE-Grid) format with a $0.25^{\circ}$ spatial resolution (NASA National Snow and Ice Data Center Distributed Active Archive Center, http:/ / nsidc.org/data/AE_Land3/versions/2), and the Japan Aerospace Exploration Agency (JAXA) AMSR2 daily level-3 land surface soil moisture products in the Equidistant-Cylindrical Rectangular (EQR) format with a $0.25^{\circ}$ spatial resolution (Global Change Observation Mission, http:/ /gcom-w1.jaxa.jp) were utilized in this study [43]. The temporal coverage of the AMSR-E products is from June 2002 to 
October 2011, while the AMSR2 is from May 2012 to present. As a follow-up passive microwave sensor, the AMSR2 can be used as a continuous dataset with AMSR-E [44]. The gridded products include daily measurements of brightness temperatures, sea surface temperature, wind speed, as well as land surface soil moisture and quality control variables. The passive microwave remote-sensing products used as original data in the soil freeze and thaw discrimination are the $18.7 \mathrm{GHz}$ and $36.5 \mathrm{GHz}$ vertically polarized brightness temperature and surface soil moisture products. The detailed specifications of the data used in this study are listed in Table 1.

Table 1. The detailed specifications of the AMSR-E and AMSR2 products.

\begin{tabular}{|c|c|c|c|c|c|}
\hline Data Type & Data & $\begin{array}{c}\text { Spatial } \\
\text { Resolution }\end{array}$ & $\begin{array}{l}\text { Temporal } \\
\text { Resolution }\end{array}$ & Time Range & Application \\
\hline \multirow{3}{*}{ AMSR-E } & $\mathrm{SM}^{1}$ & $0.25^{\circ}$ & Daily & \multirow{3}{*}{$\begin{array}{l}\text { From } 1 \text { August 2010, to } \\
31 \text { July } 2011 \text { (P1) }\end{array}$} & $\begin{array}{l}\text { Basic data for soil } \\
\text { moisture characteristic } \\
\text { parameters extraction }\end{array}$ \\
\hline & $\mathrm{Tb} 19 \mathrm{v}^{2}$ & $0.25^{\circ}$ & Daily & & $\begin{array}{l}\text { Original data for freeze } \\
\text { and thaw discrimination }\end{array}$ \\
\hline & $\mathrm{Tb} 37 \mathrm{v}^{3}$ & $0.25^{\circ}$ & Daily & & $\begin{array}{l}\text { Original data for freeze } \\
\text { and thaw discrimination }\end{array}$ \\
\hline \multirow{3}{*}{ AMSR2 } & SM & $0.25^{\circ}$ & Daily & \multirow{3}{*}{$\begin{array}{l}\text { From } 1 \text { August 2012, to } \\
31 \text { July } 2013(\mathrm{P} 2) \\
\text { and } \\
\text { from } 1 \text { August 2013, to } \\
31 \text { July } 2014 \text { (P3) }\end{array}$} & $\begin{array}{l}\text { Basic data for soil } \\
\text { moisture characteristic } \\
\text { parameters extraction }\end{array}$ \\
\hline & $\mathrm{Tb} 19 \mathrm{v}$ & $0.25^{\circ}$ & Daily & & $\begin{array}{l}\text { Original data for freeze } \\
\text { and thaw discrimination }\end{array}$ \\
\hline & $\mathrm{Tb} 37 \mathrm{v}$ & $0.25^{\circ}$ & Daily & & $\begin{array}{l}\text { Original data for freeze } \\
\text { and thaw discrimination }\end{array}$ \\
\hline
\end{tabular}

${ }^{1} \mathrm{SM}$ represents soil moisture. ${ }^{2} \mathrm{~Tb} 19 \mathrm{v}$ represents the $18.7 \mathrm{GHz}$ vertically polarized brightness temperature. ${ }^{3} \mathrm{~Tb} 37 \mathrm{v}$ represents the $36.5 \mathrm{GHz}$ vertically polarized brightness temperature.

The AMSR-E soil moisture product was retrieved by using C-band $(6.9 \mathrm{GHz})$ and X-band (10.7 GHz) brightness temperatures following the algorithm by Njoku et al. [43]. The local solar times of ascending and descending orbits of Aqua across the equator are about 1:30 p.m. and 1:30 a.m. The retrieval accuracy of the AMSR-E soil moisture product is less than the Root Mean Square Error (RMSE) of $0.06 \mathrm{~m}^{3} \cdot \mathrm{m}^{-3}$. Because vegetation also contains moisture, attenuation from vegetation increases the retrieval error in soil moisture [45]. The study area is mainly covered with sparse vegetation of alpine shrubs, alpine meadows, and alpine grasslands [46]. Fortunately, sparse vegetation cover in the cold elevations of the plateau guarantees the accuracy of the AMSR-E soil moisture product for this region. AMSR2 soil moisture product was estimated by using X-band (10.7 GHz) and Ka-band (36.5 GHz) brightness temperatures as employed by Fujii et al. [47] by introducing the vegetation fractional area into the soil moisture retrieved algorithm to consider the effects of vegetation cover. This algorithm showed the basis for the AMSR2 soil moisture algorithm. Zeng et al. [48] proved that the JAXA AMSR2 product could capture the soil moisture temporal dynamics better than the NASA AMSR-E product by evaluating the two kinds of soil moisture products over the Tibetan Plateau.

\subsection{DIA}

The original and improved versions of the DIA proposed by Zuerndorfer, et al. (1990) involved two parameters for the description of frozen ground surfaces. The core algorithm can be summarized in Equations (1) and (2).

$$
\begin{gathered}
T b_{37 v} \leq P_{37} \\
\frac{\partial}{\partial f} T b(f) \leq P_{S G}
\end{gathered}
$$


where $T b_{37 v}$ represents vertical polarization brightness temperatures at $37 \mathrm{GHz}(\mathrm{K})$, and $\frac{\partial}{\partial f} T b(f)$ the negative spectral gradient between $19 \mathrm{GHz}$ and $37 \mathrm{GHz}\left(\mathrm{K} \cdot \mathrm{GHz}^{-1}\right) . P_{37}$ and $P_{\mathrm{SG}}$ stand for the thresholds of two indicators of $T b_{37 v}$ and $\frac{\partial}{\partial f} T b(f)$, respectively. Usually, the value of $P_{S G}$ is set to zero. When the condition for Equations (1) and (2) is satisfied simultaneously, the ground surface can be identified as freezing, otherwise, it's thawing.

Overall, more than 4000 measurements over 12 blocks were used in this study. Figure 3 illustrated the time series of $\mathrm{Tb} 37 \mathrm{v}$ and ground-based measurements of soil temperature and moisture at stations L9 and L27 for 1 August 2010 to 31 July 2011. The ground-based measurements of soil temperature and moisture were illustrated in the same figure to help better characterize the surface soil freeze/thaw states. Generally, in order to simplify the analysis, the ground surface can be treated as frozen when the soil temperature at $5 \mathrm{~cm}$ reaches below $0{ }^{\circ} \mathrm{C}$. As can be seen in Figure 3, the freezing period in the study area typically started from late October and ended in early April of the following year. $\mathrm{Tb} 37 \mathrm{v}$ and SG shared many similarities in the two stations on frozen and thawed ground surfaces. However, the hydrothermal conditions differed over specific periods of time. Both indicators manifested a significant spatial and temporal variability, which fluctuated with the phase transition between liquid water and ice. Additionally, some Tv37v and SG anomalies were detected at the L27 station over the transition periods between freezing and thawing with a sharp drop in the soil moisture, implying a relationship between soil moisture and brightness temperature.
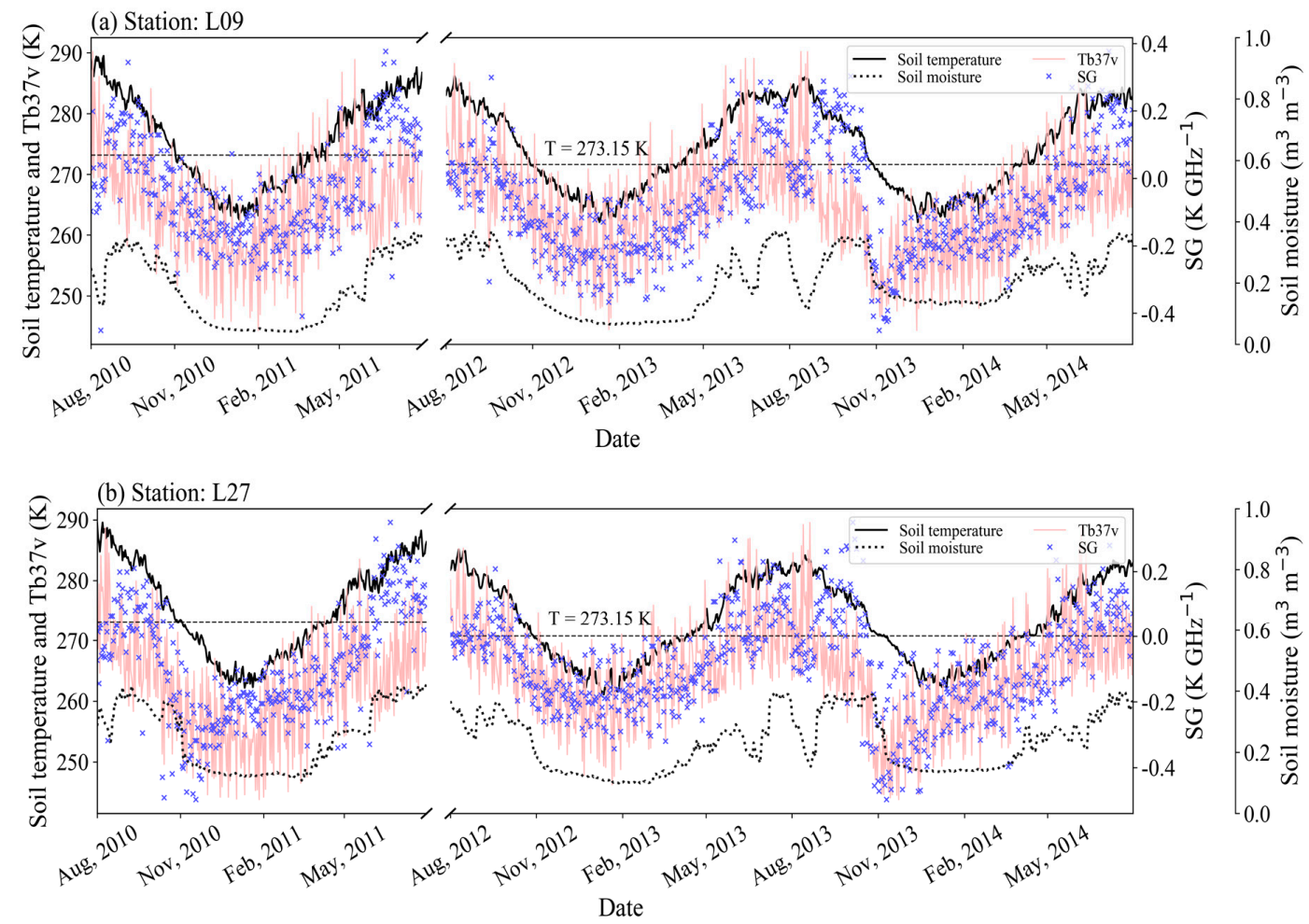

Figure 3. Time series of Tb37v and ground-based measurements of soil temperature and moisture at Station L9 (a) and Station L27 (b) over the study periods.

To determine the threshold of Tb37v, the correlation between the ground-based measurements of the soil temperature at depth of $5 \mathrm{~cm}$ and $\mathrm{Tb} 37 \mathrm{v}$ derived from the satellite observations over the study periods was calculated, and the results are shown in Figure 4.

As exhibited in Figure 4, only a moderate correlation was found between the soil temperature at $5 \mathrm{~cm}$ depth and a Tb37v index with $R_{P 1}=0.64$ and $R_{P 2, P 3}=0.65$. The threshold of $\operatorname{Tb} 37 \mathrm{v}\left(P_{37}\right)$ for two time periods (time series of AMSR-E and AMSR2 products) can be estimated around a soil temperature of $257.60 \mathrm{~K}$ ranging from $250.00 \mathrm{~K}$ to $265.20 \mathrm{~K}$ and $258.69 \mathrm{~K}$ ranging from $251.24 \mathrm{~K}$ to $266.14 \mathrm{~K}$. 
This moderate correlation can be attributed to the following reasons. First of all, the influence of snow cover on the freeze/thaw states of the underlying soil was not included in the analysis of the passive microwave data. Secondly, the temporal variability of Tb37v is one of the characteristics of AMSR-E and AMSR2 brightness temperature data products, which have different characteristics compared with the observed values [43]. Consequently, this becomes one of the inherent disadvantages of the DIA, which results in uncertainties in surface soil freeze/thaw state discriminations. This shortcoming is the main point of focus in this study that must be overcome.
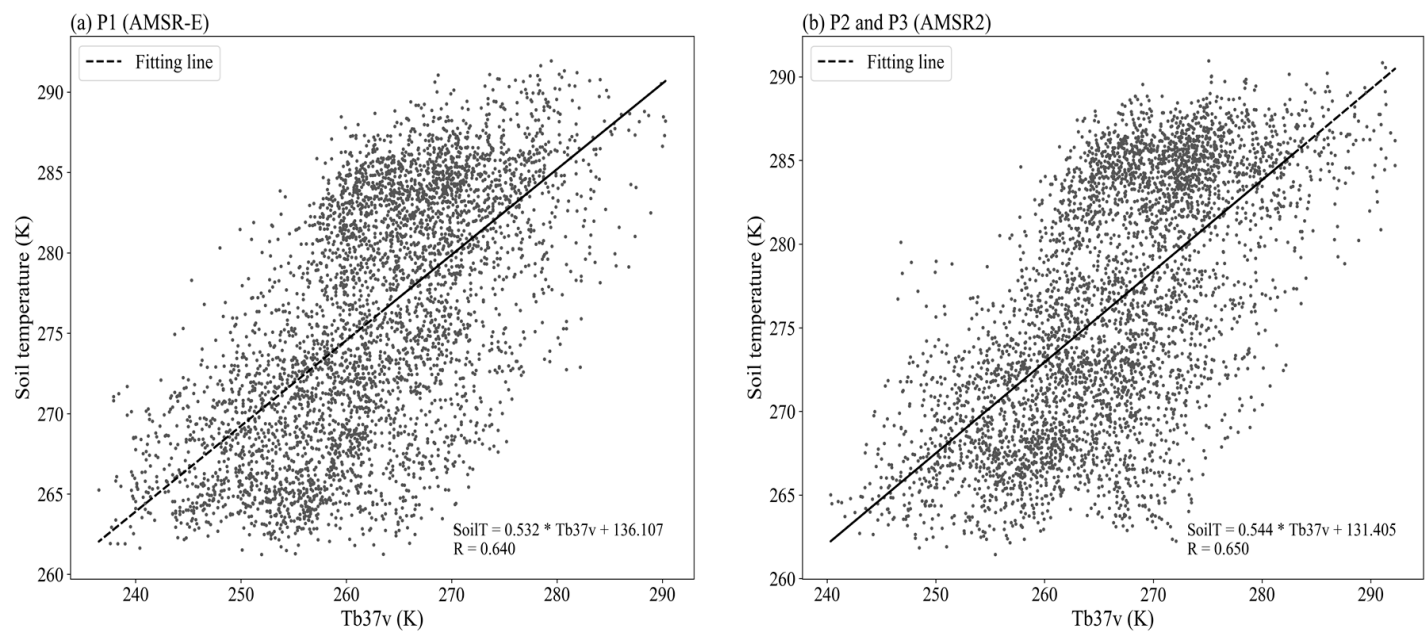

Figure 4. The linear relationship between soil temperature and Tb37v over the periods of P1 (a) and P2, P3 (b).

\subsection{Soil Moisture Characteristics}

Soil moisture significantly affects seasonal patterns of surface soil freeze/thaw states [49-51]. The seasonal variations of the mean daily soil moisture values, measured at $5 \mathrm{~cm}$ soil depth in 12 stations over the area, were used to characterize the spatial and temporal variations of this parameter. The results were plotted with different colors in Figure 5 to illustrate the observed fluctuations of this parameter, where the solid blue line, solid red line, and blue filled area represent the variations of the averaged soil moisture, averaged soil temperature, and variance of soil moisture in 12 stations, respectively, over the study periods. As shown, there was an evident temporal and spatial variability of soil moisture over the experiment site. This variability implied that the limited in-situ observations could result in a considerable error in the quality assessment of soil moisture products. Furthermore, dramatic seasonal variations of soil moisture in summer (between $0.1 \mathrm{~m}^{3} \cdot \mathrm{m}^{-3}$ to $0.6 \mathrm{~m}^{3} \cdot \mathrm{m}^{-3}$ ) and slight variations in winter (between 0 to $0.2 \mathrm{~m}^{3} \cdot \mathrm{m}^{-3}$ ) gave a clear indication of the significant differences between soil moisture content in the frozen and thawed soils.

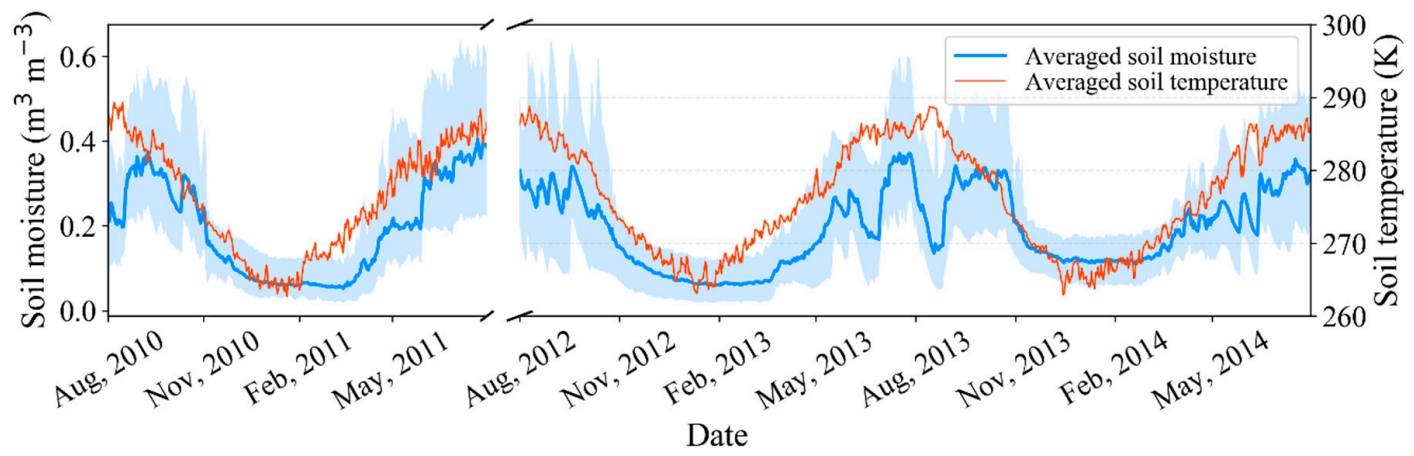

Figure 5. The seasonal variations of mean daily soil moisture measured at $5 \mathrm{~cm}$ in 12 stations over the study area. 


\subsection{Soil Moisture Characteristic Parameter Extraction}

The temporal and spatial heterogeneity of soil moisture marks the complexity of its influence on climate change and hydrology. A simple statistical indicator [38] of the local variation of the soil moisture was adopted to evaluate the seasonal fluctuations of the data series in this study. Local variance, as the measure of the fluctuation of datasets within a specific period, is the most widely used digital processing technique, especially in graphics and image processing [40,52]. Unlike a local variance parameter in image interpretation in two dimensions, the local variance of soil moisture (LVSM) should be assessed from both spatial and temporal aspects. The local variance of soil moisture, therefore, can be represented by Equations (3) and (4).

$$
\begin{aligned}
\operatorname{LVSM}_{(k, i, j)} & =\frac{1}{\lambda} \sum_{p=k}^{k+\lambda}\left(\eta_{(p, i, j)}-\mu_{\lambda}\right)^{2} \\
\mu_{\lambda} & =\frac{1}{\lambda} \sum_{p=k}^{k+\lambda} \eta_{(p, i, j)}
\end{aligned}
$$

where, $\operatorname{LVSM}_{(k, i, j)}$ is the local variance of soil moisture $\left(\mathrm{m}^{3} \cdot \mathrm{m}^{-3}\right)$ at $(i, j)$ at time $k ; \eta$ is the pixel value of soil moisture at pixel $(i, j)$ at time $p ; \lambda$ is a fixed partial time span (days) of the time series used to calculate local variance; and, $\mu_{\lambda}$ is the average value of soil moisture over the time span. We assigned different values (e.g., 5, 10, 15, . , 45 and 50) to $\lambda$ to calculate LVSM. The value explaining the largest variations in seasonal LVSM was selected as an appropriate $\lambda$. Finally, $\lambda$ was found to be 25 in this study.

It should be noted that the fixed partial time span of the time series $\lambda$, similar to a sliding window, was used to calculate the local variance from the beginning to the end of the time series. In this process, the sliding window has two positions (before or after the unresolved pixel, except for the first and the last day) relative to an unresolved pixel. The local variances of each pixel, if available, were calculated at two positions, and then the minimum value was selected as the local variance of this pixel. $\operatorname{LVSM}_{(k, i, j)}^{a}$ and $\operatorname{LVSM}_{(k, i, j)}^{b}$ represented the local variances of the two positions at $(k, i, j)$, respectively. This approach can be represented by Equation (5).

$$
\operatorname{LVSM}_{(k, i, j)}=\left\{\begin{array}{lc}
\operatorname{LVSM}_{(k, i, j)}^{b} & , \lambda<k \leq L-\lambda \\
\min \left(\operatorname{LVSM}_{(k, i, j)}^{a}, \operatorname{LVSM}_{(k, i, j)}^{b}\right), & k \leq \lambda \\
\operatorname{LVSM}_{(k, i, j)}^{a} & , \quad k>L-\lambda
\end{array}\right.
$$

where, $L$ is the total length of the time series.

\subsection{Improvement of the DIA by Using LVSM}

Integrating LVSM with the DIA to further improve the performance of the DIA is a key issue in this study. The LVSM based on the passive microwave soil moisture products were derived by the approach described above, and the result was plotted in Figure 6 together with time series of the AMSR-E and ASMR2 soil moisture products and in-situ temperature products at station L9 (a) and L27 (b). The result exhibited different temporal variation characteristics under different passive microwave soil moisture products between AMSR-E and AMSR2. Even so, it can be noted that most of the LVSM values were comparatively higher in summer and reasonably lower and with fewer fluctuations in winter over the entirety of the three year period of the study. Compared with soil temperature variations, LVSM values fluctuated dramatically in thawed soils but remained constant at a low level in frozen ground surfaces.

The scatter plot of LVSM along with the corresponding cluster data of Tb37v and SG were displayed in Figure 7. In this figure, darker cluster data points indicate higher LVSM values. 
According to the soil temperature, the cluster data points were divided into two regions, namely, the frozen ground $\left(A_{1}\right)$ and the thawed ground $\left(A_{2}\right)$. As indicated, a large proportion of high LVSM values are scattered in region $A_{2}$, while most of the data with low LVSM values were concentrated in region $\mathrm{A}_{1}$. This finding, which was inconsistent with the hypothesis that the LVSM values always stay at a low level in the frozen ground surfaces and was the main issue with the original DIA in discriminating freeze/thaw cycles.
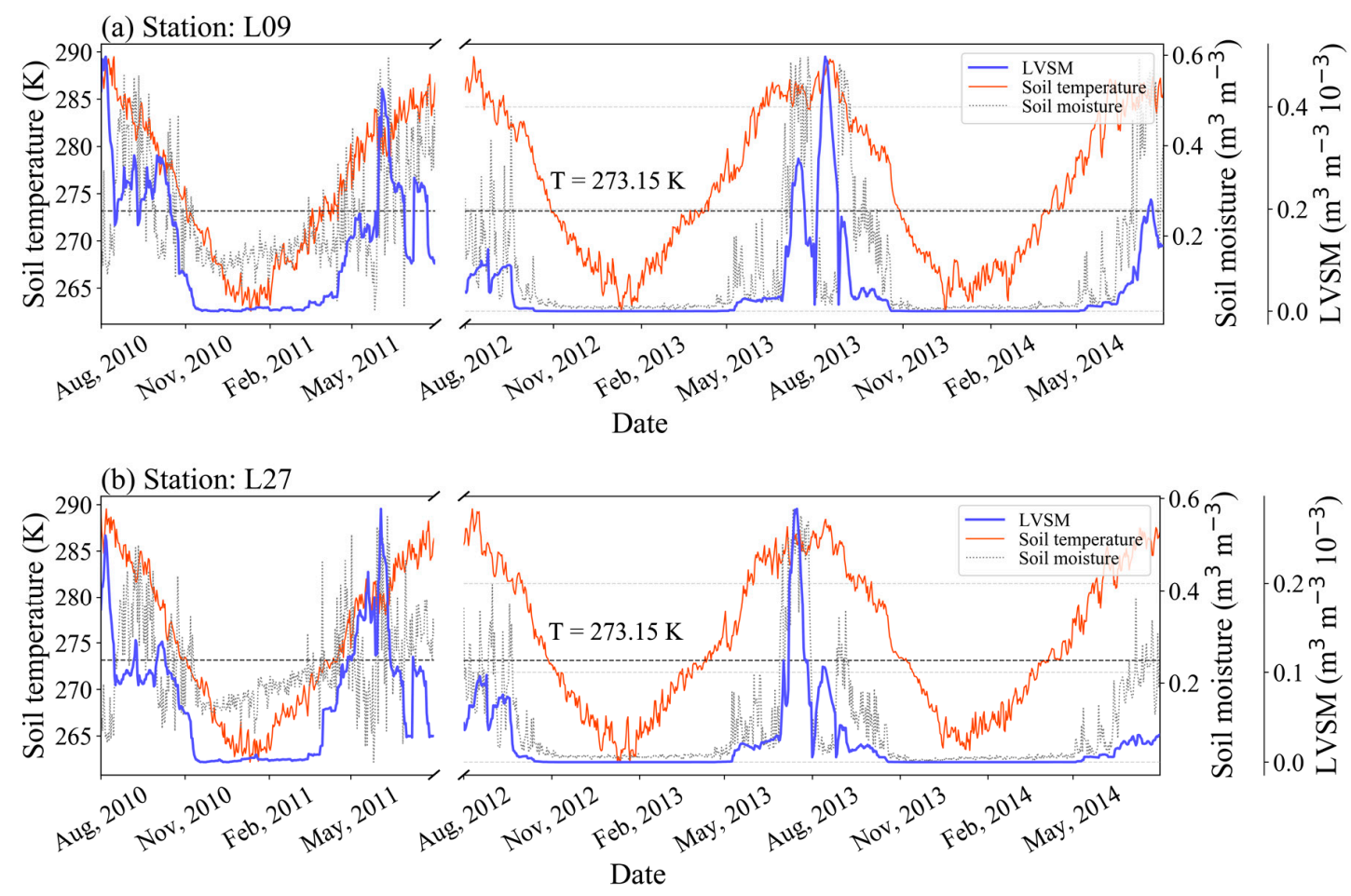

Figure 6. Seasonal variations of local variance of soil moisture (LVSM), AMSR-E, and AMSR2 soil moisture products and soil temperature products at station L9 (a) and L27 (b).
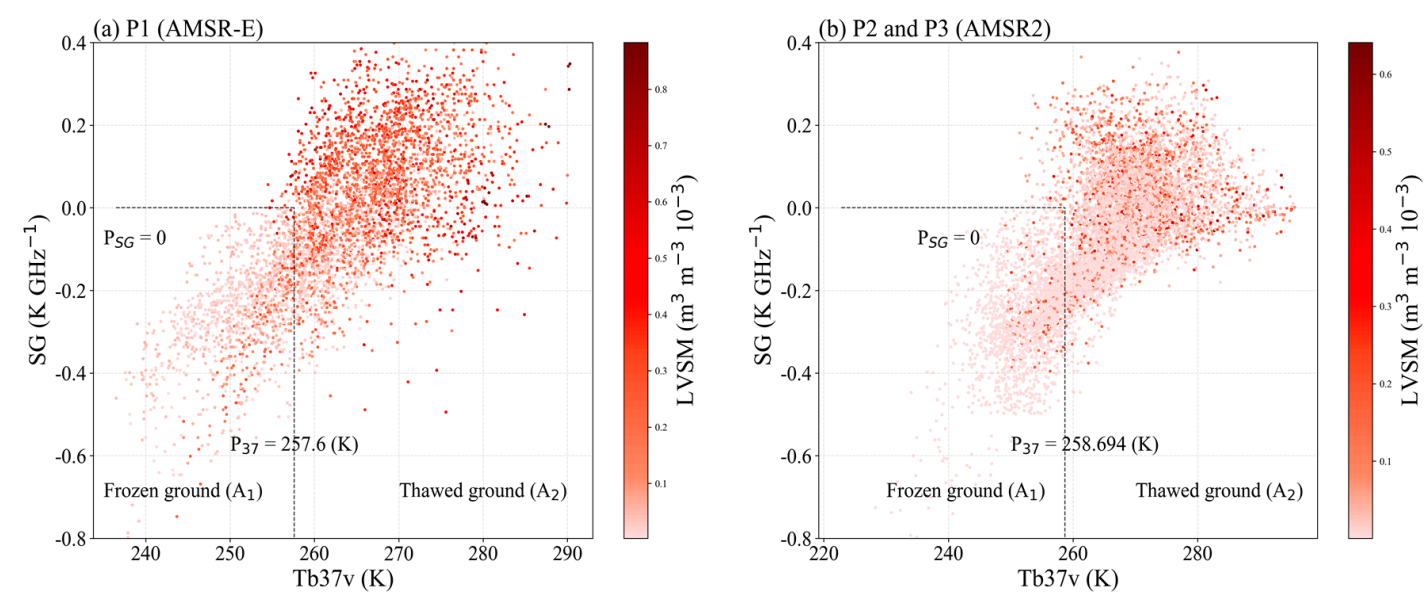

Figure 7. The scatter plot of LVSM along with corresponding cluster data of $\mathrm{Tb} 37 \mathrm{v}$ and spectral gradient (SG) over the periods of P1 (a) and P2, P3 (b).

Several tactics are possible to improve the original DIA by taking LVSM into account. For example, one could adjust the threshold of Tb37v and SG by statistical analysis of the relationship between LVSM and the two indices of the original DIA, or modify the results of the original DIA through LVSM directly. Lastly, with regard to the characteristics of LVSM, the second approach was selected, 
which involved integrating the LVSM as a correction index with the original DIA to reduce uncertainty. The procedure to improve the original DIA by taking LVSM into account can be summarized as follows: (1) Constructing the temporal and spatial sequence of ground-based soil temperature over the 12 stations; (2) Extracting LVSM values at the soil temperature of $0{ }^{\circ} \mathrm{C}$ and organizing them as an array; (3) Assigning the maximum value of this array as a new threshold to update the results of the DIA. Through this procedure, the new threshold was determined as 0.168.

\section{Results}

\subsection{Performance Comparisons of the Improved Algorithm with Original DIA over the Experiment Site}

Daily surface soil freeze/thaw states from 1st August 2010 to 31st July 2011 over the experiment site were discriminated with the improved algorithm based on passive microwave soil moisture products (AMSR-E and AMSR2 products) as described in Section 2. Correspondingly, initial days (date and day of the year (DOY)) of soil freeze and thaw at each station over the study periods can be obtained through classification of the discriminated surface soil freeze/thaw states' images. The soil temperature slightly fluctuated around $0{ }^{\circ} \mathrm{C}$ over the experiment period. Thus, the first day of the period, when the ground surface remained frozen or thawed for longer than three days, was defined as the initial day. The starting dates and DOY of soil freeze and thaw at 12 stations are shown in Table 2. The initial days obtained for soil freezing and thawing by the improved and original DIA had a considerable difference.

Table 2. Initial days of soil freezing and thawing at 12 stations.

\begin{tabular}{|c|c|c|c|c|c|c|c|}
\hline \multirow{2}{*}{$\begin{array}{l}\text { Study } \\
\text { Period }\end{array}$} & \multirow[b]{2}{*}{ Sta. ${ }^{1}$} & \multicolumn{3}{|c|}{ Initial Days (Date/DOY) of Soil Freezing } & \multicolumn{3}{|c|}{ Initial Days (Date/DOY) of Soil Thawing } \\
\hline & & $\begin{array}{l}\text { Improved } \\
\text { Algorithm }\end{array}$ & DIA & $\begin{array}{l}\text { SMTMN } \\
\text { obs. }{ }^{2}\end{array}$ & $\begin{array}{l}\text { Improved } \\
\text { Algorithm }\end{array}$ & DIA & $\begin{array}{c}\text { SMTMN } \\
\text { obs. }\end{array}$ \\
\hline \multirow{13}{*}{ P1 } & L1 & 03 Nov / 307 & $12 \mathrm{Oct} / 285$ & $02 \mathrm{Nov} / 306$ & $29 \mathrm{Mar} / 088$ & $29 \mathrm{Mar} / 088$ & $01 \mathrm{Apr} / 091$ \\
\hline & L9 & 03 Nov $/ 307$ & $12 \mathrm{Oct} / 285$ & 03 Nov $/ 307$ & $29 \mathrm{Mar} / 088$ & $29 \mathrm{Mar} / 088$ & $01 \mathrm{Apr} / 091$ \\
\hline & L11 & 01 Nov/305 & $12 \mathrm{Oct} / 285$ & 03 Nov $/ 307$ & $29 \mathrm{Mar} / 088$ & $29 \mathrm{Mar} / 088$ & $19 \mathrm{Mar} / 078$ \\
\hline & L14 & 03 Nov $/ 307$ & $12 \mathrm{Oct} / 285$ & 04 Nov/308 & $24 \mathrm{Mar} / 083$ & $24 \mathrm{Mar} / 083$ & $19 \mathrm{Mar} / 078$ \\
\hline & L19 & 28 Oct/301 & $05 \mathrm{Oct} / 278$ & $04 \mathrm{Nov} / 308$ & $02 \mathrm{Apr} / 092$ & 16 May/136 & $31 \mathrm{Mar} / 090$ \\
\hline & L23 & 12 Sep $/ 255$ & $25 \mathrm{Aug} / 237$ & 05 Nov $/ 309$ & $02 \mathrm{Apr} / 092$ & 17 Jun/168 & $16 \mathrm{Mar} / 075$ \\
\hline & L26 & 10 Sep/253 & 10 Sep/253 & 04 Nov /308 & $18 \mathrm{Apr} / 108$ & 04 May/124 & $18 \mathrm{Apr} / 108$ \\
\hline & L27 & $28 \mathrm{Oct} / 301$ & $12 \mathrm{Oct} / 285$ & 29 Oct/302 & $24 \mathrm{Mar} / 083$ & $24 \mathrm{Mar} / 083$ & $12 \mathrm{Apr} / 102$ \\
\hline & L30 & 28 Oct/301 & $12 \mathrm{Oct} / 285$ & 04 Nov/308 & 02 Apr/092 & 04 May/124 & $25 \mathrm{Mar} / 084$ \\
\hline & L32 & 04 Nov/308 & $12 \mathrm{Oct} / 285$ & 04 Nov/308 & $24 \mathrm{Mar} / 083$ & $24 \mathrm{Mar} / 083$ & 19 Mar/078 \\
\hline & L35 & 28 Oct/301 & $12 \mathrm{Oct} / 285$ & 04 Nov/308 & $29 \mathrm{Mar} / 088$ & $29 \mathrm{Mar} / 088$ & $27 \mathrm{Mar} / 086$ \\
\hline & L37 & 10 Sep/253 & 08 Sep/251 & 04 Nov/308 & 09 May/129 & 17 Jun/168 & $17 \mathrm{Mar} / 076$ \\
\hline & L1 & 02 Nov/307 & $26 \mathrm{Oct} / 300$ & 01 Nov/306 & 19 Apr/109 & 19 Apr/109 & 09 Apr/099 \\
\hline \multirow{11}{*}{ P2 } & L9 & 02 Nov/307 & $16 \mathrm{Sep} / 260$ & 30 Oct/304 & 19 Apr/109 & 19 Apr/109 & 29 Mar/088 \\
\hline & L11 & 26 Oct $/ 300$ & $08 \mathrm{Oct} / 282$ & 02 Nov/307 & 19 Apr/109 & 19 Apr/109 & $15 \mathrm{Mar} / 074$ \\
\hline & L14 & 02 Nov/307 & $10 \mathrm{Oct} / 284$ & 06 Nov /311 & $03 \mathrm{Apr} / 093$ & 03 Apr/093 & $15 \mathrm{Mar} / 074$ \\
\hline & L19 & 28 Oct/302 & $12 \mathrm{Oct} / 286$ & 07 Nov / 312 & $05 \mathrm{Apr} / 095$ & 07 May/127 & $22 \mathrm{Mar} / 081$ \\
\hline & L23 & 24 Oct $/ 298$ & 21 Aug/234 & 30 Oct/304 & $12 \mathrm{Apr} / 102$ & 25 May/145 & $10 \mathrm{Apr} / 100$ \\
\hline & L26 & 24 Oct/298 & $10 \mathrm{Oct} / 284$ & 03 Nov/308 & 19 Apr/109 & 19 Apr/109 & $10 \mathrm{Apr} / 100$ \\
\hline & L27 & 02 Nov/307 & $12 \mathrm{Oct} / 286$ & 29 Oct/303 & $03 \mathrm{Apr} / 093$ & 03 Apr/093 & 13 Apr/103 \\
\hline & L30 & 28 Oct/302 & $10 \mathrm{Oct} / 284$ & 30 Oct $/ 304$ & $03 \mathrm{Apr} / 093$ & 03 Apr/093 & 14 Mar/073 \\
\hline & L32 & 25 Oct $/ 299$ & 19 Oct $/ 293$ & 30 Oct/304 & $22 \mathrm{Mar} / 081$ & 19 Apr/109 & $15 \mathrm{Mar} / 074$ \\
\hline & L35 & 25 Oct $/ 299$ & $08 \mathrm{Oct} / 282$ & 09 Nov/314 & 19 Apr/109 & 5 May/125 & $29 \mathrm{Mar} / 088$ \\
\hline & L37 & 22 Oct $/ 296$ & 21 Aug/234 & $30 \mathrm{Oct} / 304$ & $20 \mathrm{Apr} / 110$ & 28 May/148 & $14 \mathrm{Mar} / 073$ \\
\hline \multirow{7}{*}{ P3 } & L1 & 26 Oct/299 & 04 Oct $/ 277$ & 31 Oct/304 & 03 May/123 & 24 May/083 & 06 Apr/096 \\
\hline & L9 & 02 Nov/306 & 20 Oct $/ 293$ & 30 Oct $/ 303$ & 30 Mar/089 & $30 \mathrm{Mar} / 089$ & 31 Mar/090 \\
\hline & L11 & 20 Oct / 293 & 06 Oct $/ 279$ & 31 Oct/302 & 03 May/123 & 03 May/123 & $26 \mathrm{Mar} / 085$ \\
\hline & L14 & $22 \mathrm{Oct} / 295$ & $22 \mathrm{Oct} / 295$ & $31 \mathrm{Oct} / 302$ & 23 Mar/082 & $23 \mathrm{Mar} / 082$ & $27 \mathrm{Mar} / 086$ \\
\hline & L19 & $22 \mathrm{Oct} / 295$ & $22 \mathrm{Oct} / 295$ & 03 Nov / 307 & $10 \mathrm{Feb} / 041$ & 10 Feb/041 & $28 \mathrm{Mar} / 087$ \\
\hline & L23 & $22 \mathrm{Oct} / 295$ & $15 \mathrm{Oct} / 288$ & 08 Nov/312 & $25 \mathrm{Mar} / 084$ & $25 \mathrm{Mar} / 084$ & $06 \mathrm{Apr} / 096$ \\
\hline & L26 & 20 Oct $/ 293$ & $15 \mathrm{Oct} / 288$ & 05 Nov/309 & $23 \mathrm{Mar} / 082$ & $23 \mathrm{Mar} / 082$ & $06 \mathrm{Apr} / 096$ \\
\hline
\end{tabular}


Table 2. Cont.

\begin{tabular}{cccccccc}
\hline \multirow{2}{*}{$\begin{array}{c}\text { Study } \\
\text { Period }\end{array}$} & Sta. ${ }^{1}$ & \multicolumn{2}{c}{ Initial Days (Date/DOY) of Soil Freezing } & \multicolumn{2}{c}{ Initial Days (Date/DOY) of Soil Thawing } \\
\cline { 3 - 8 } & & $\begin{array}{l}\text { Improved } \\
\text { Algorithm }\end{array}$ & DIA & $\begin{array}{c}\text { SMTMN } \\
\text { obs. }{ }^{2}\end{array}$ & $\begin{array}{c}\text { Improved } \\
\text { Algorithm }\end{array}$ & DIA & $\begin{array}{c}\text { SMTMN } \\
\text { obs. }\end{array}$ \\
\hline \multirow{4}{*}{ P3 } & L27 & $20 \mathrm{Oct} / 293$ & $15 \mathrm{Oct} / 288$ & $08 \mathrm{Nov} / 312$ & $23 \mathrm{Mar} / 082$ & $23 \mathrm{Mar} / 082$ & $06 \mathrm{Apr} / 096$ \\
& $\mathrm{~L} 30$ & $22 \mathrm{Oct} / 293$ & $22 \mathrm{Oct} / 295$ & $31 \mathrm{Oct} / 304$ & $10 \mathrm{Feb} / 041$ & $10 \mathrm{Feb} / 041$ & $28 \mathrm{Mar} / 087$ \\
& $\mathrm{~L} 32$ & $20 \mathrm{Oct} / 293$ & $20 \mathrm{Oct} / 293$ & $08 \mathrm{Nov} / 312$ & $26 \mathrm{Feb} / 057$ & $26 \mathrm{Feb} / 057$ & $26 \mathrm{Mar} / 085$ \\
& $\mathrm{~L} 35$ & $20 \mathrm{Oct} / 293$ & $06 \mathrm{Oct} / 279$ & $04 \mathrm{Nov} / 308$ & $03 \mathrm{May} / 123$ & $03 \mathrm{May} / 123$ & $29 \mathrm{Mar} / 088$ \\
& $\mathrm{~L} 37$ & $20 \mathrm{Oct} / 293$ & $04 \mathrm{Oct} / 277$ & $31 \mathrm{Oct} / 304$ & $08 \mathrm{Apr} / 098$ & $03 \mathrm{May} / 123$ & $17 \mathrm{Mar} / 076$ \\
\hline
\end{tabular}

${ }^{1}$ Sta. is an abbreviation for "Station". ${ }^{2}$ obs. is an abbreviation for "observation". Feb, Mar, Apr, Jun, Aug, Sep, Oct, and Nov are abbreviations for February, March, April, June, August, September, October, November, respectively.

A total number of 3240 pixels with frozen soils (from 20th September to 5th November) and thawing (from 5th April to 20th May) with the duration of approximately 90 days in each year at each station were selected to validate the improved algorithm. The validated results at the 12 stations over the period from 1st August 2010 to 31st July 2011 and 1st August 2012 to 31st July 2014 were listed in Table 3. The accuracy obtained for the improved algorithm in the range of $71.1 \%$ to $98.9 \%$ was generally higher than that of the original DIA ranging from $63.3 \%$ to $96.7 \%$. In total, the application of the improved algorithm resulted in 356 incorrectly discriminated pixels with an average discrimination accuracy of $89.0 \%$. Using the original approach produced 588 incorrectly discriminated pixels with an average accuracy of $81.9 \%$. A frequency histogram of the observed soil temperatures over the incorrectly discriminated pixels is presented in Figure 8.

Table 3. Validation of the discrimination results by in situ observations at 12 stations over the period of 1st August 2010 to 31st July 2011 and 1st August 2012 to 31st July 2014.

\begin{tabular}{|c|c|c|c|c|c|c|c|}
\hline \multirow[b]{2}{*}{ Study Period } & \multirow[b]{2}{*}{ Sta. } & \multicolumn{3}{|c|}{ DIA } & \multicolumn{3}{|c|}{ Improved Algorithm } \\
\hline & & Validation & $\begin{array}{c}\text { Incorrect } \\
\text { Discrimination }\end{array}$ & $\begin{array}{c}\text { Accuracy } \\
(\%)\end{array}$ & Validation & $\begin{array}{c}\text { Incorrect } \\
\text { Discrimination }\end{array}$ & $\begin{array}{c}\text { Accuracy } \\
(\%)\end{array}$ \\
\hline \multirow{8}{*}{ P1 } & L9 & 90 & 9 & 90.0 & 90 & 4 & 95.6 \\
\hline & L11 & 90 & 8 & 91.1 & 90 & 3 & 96.7 \\
\hline & L14 & 90 & 7 & 94.4 & 90 & 2 & 97.8 \\
\hline & L23 & 90 & 27 & 70.0 & 90 & 12 & 86.7 \\
\hline & L26 & 90 & 24 & 73.3 & 90 & 15 & 83.3 \\
\hline & L27 & 90 & 22 & 75.6 & 90 & 14 & 84.4 \\
\hline & L30 & 90 & 14 & 84.4 & 90 & 4 & 95.6 \\
\hline & L32 & 90 & 3 & 96.7 & 90 & 1 & 98.9 \\
\hline \multirow{11}{*}{ P2, P3 } & L1 & 180 & 42 & 76.7 & 180 & 29 & 83.9 \\
\hline & L9 & 180 & 23 & 87.2 & 180 & 15 & 91.7 \\
\hline & L11 & 180 & 28 & 84.5 & 180 & 16 & 91.1 \\
\hline & L14 & 180 & 12 & 93.3 & 180 & 11 & 93.9 \\
\hline & L19 & 180 & 28 & 84.5 & 180 & 14 & 92.2 \\
\hline & L23 & 180 & 41 & 77.3 & 180 & 25 & 86.2 \\
\hline & L26 & 180 & 43 & 76.1 & 180 & 28 & 84.5 \\
\hline & L27 & 180 & 34 & 81.1 & 180 & 30 & 83.3 \\
\hline & L30 & 180 & 26 & 85.6 & 180 & 21 & 88.4 \\
\hline & L32 & 180 & 24 & 86.7 & 180 & 19 & 89.5 \\
\hline & L35 & 180 & 38 & 78.9 & 180 & 23 & 87.2 \\
\hline
\end{tabular}




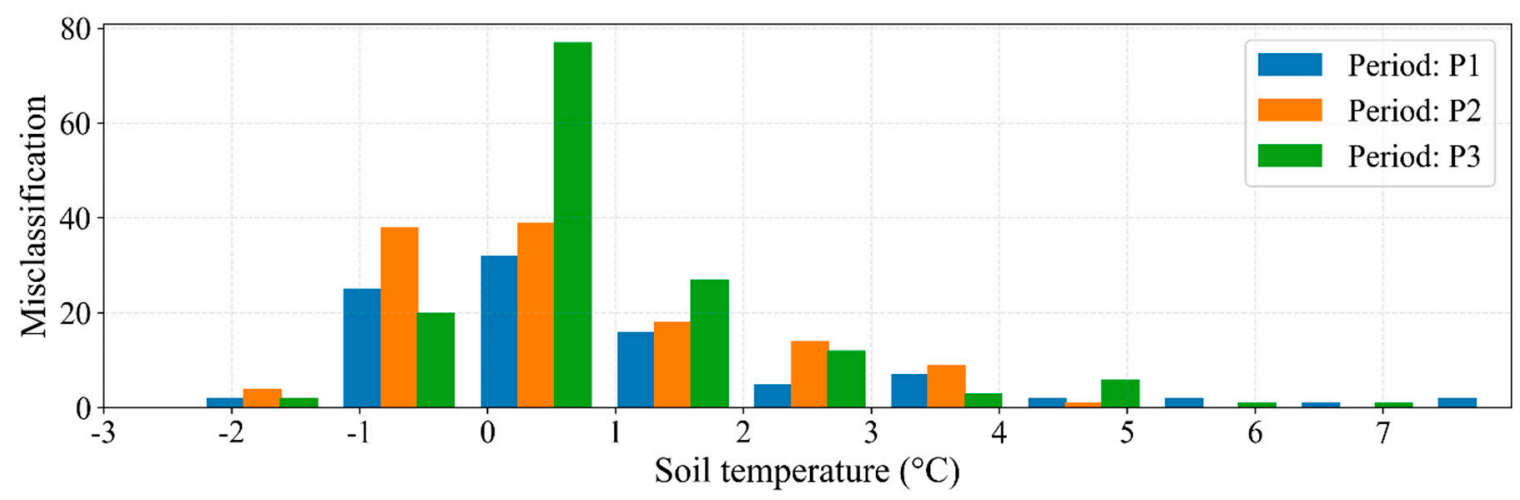

Figure 8. Frequency histogram of the observed soil temperatures for the incorrectly discriminated pixels.

\subsection{Performance of the Improved Algorithm as Compared with the DIA over the Whole Territory of China}

The areal extent of the frozen soils over China was derived by the improved and the original DIA, respectively, and the results are shown in Figure 9. The original DIA overestimated the areal extent of the frozen soils with $1 \%$ to $60 \%$ seasonal deviations. As only the incorrectly discriminated frozen soils can be corrected by the improved algorithm, the areal extent of the frozen soil over the period from late October to early April of the following year differed between the two algorithms.

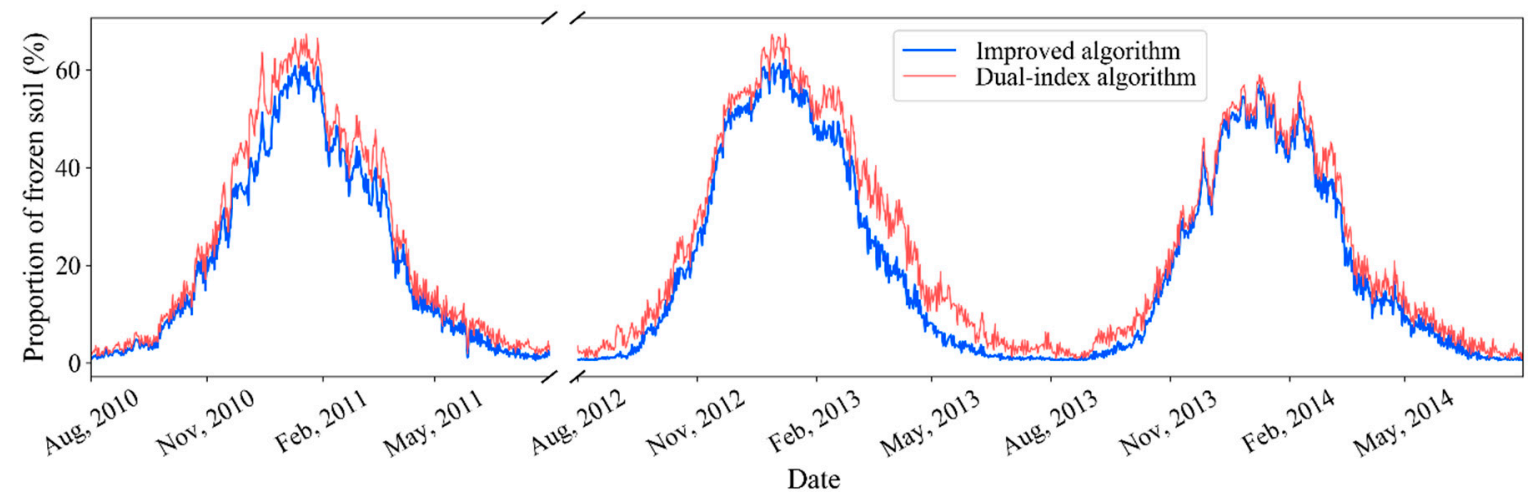

Figure 9. The areal proportions of the frozen soil over the study periods derived from the improved and original DIA, respectively.

The number of the frozen days over 1st August 2010 to 31st July 2011 and 1st August 2012 to 31st July 2014 (365 days a year) in China were calculated with the improved algorithm, and the results are exhibited in Figure 10a-c. The number of days for the frozen soils varied from 0 to 360 days over this period. The longest freezing period, ranging from 300 to 360 days, was found in the West and Northwest part of the Qinghai Tibetan Plateau where permafrost is widely distributed, and the shortest period (less than 30 days) was found in some parts of Central China and most parts of Southern China. The geocryological regionalization and classification map (2000) [53] provided by the National Earth System Science Data Sharing Infrastructure, National Science \& Technology Infrastructure of China is shown in Figure 10d.

The low brightness temperatures found near the rivers and lakes of the temperate and humid regions of China were caused by the higher soil moisture levels and the corresponding lower emissivity. Higher moisture contents can result in less accuracy when employing the brightness temperature for the discrimination of surface soil freeze/thaw states, which was the case for the areas close to the Beijing-Hangzhou Grand Canal and the Yangtze River Basin with an extensive duration of the frozen days. 

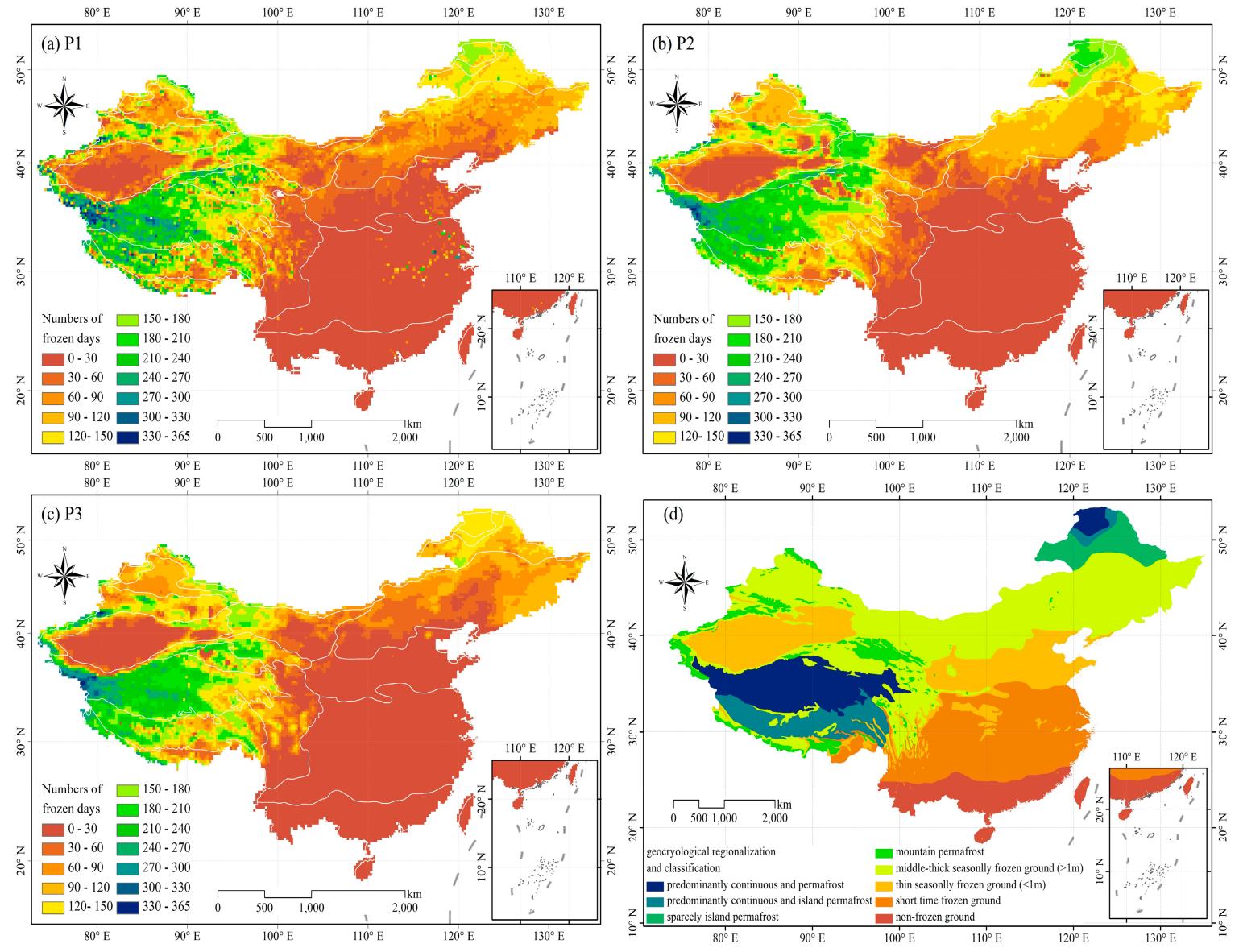

Figure 10. The numbers of days for the frozen soil in China over the study periods of P1 (a), P2 (b) and P3 (c), and the geocryological regionalization and classification of China (d) downloaded from http:/ / www.geodata.cn.

\section{Discussion}

In this study, most of the initial days of soil freezing obtained from the improved algorithm differed slightly by about 1 to 10 days when compared with the observed values of SMTMN in the time period of P1, as shown in Table 2. Nevertheless, the initial days obtained for soil thawing by the improved algorithm differed by about 1 to 20 days from the SMTMN. Even so, the results obtained by the improved algorithm were closer to those observed by SMTMN than that by the original algorithm, especially at station L26. In the time periods of P2 and P3, see Table 2, the initial days of soil freezing and thawing obtained from two algorithms had similar characteristics with the period of P1. Overall, the results of initial days of soil freezing held better reliability than that of soil thawing. The relatively poor performance of both algorithms in the determination of initial days of surface soil freeze/thaw states was attributed to the temporal and spatial differences of passive microwave data products and SMTMN observations.

The higher accuracy of the improved algorithm demonstrated its superiority in distinguishing ground surface freeze/thaw cycles, see Table 3. Approximately 250 pixels were modified by the improved algorithm during the verification stage (with 241 pixels correctly modified), which resulted in a correct classification rate for the modified pixels of higher than $96.4 \%$. It was shown that the classification performance of surface soil freeze/thaw states discrimination algorithm significantly improved by integrating with LVSM.

The incorrectly discriminated pixels were mainly distributed in the soil temperatures between $-1{ }^{\circ} \mathrm{C}$ to $1{ }^{\circ} \mathrm{C}$, which suggest that incorrect discriminations mainly occurred over the period of phase 
transition between liquid water and ice, see Figure 8. Additionally, incorrect discriminations were found to occur much more frequently in the thawed soils compared to in the frozen soils. This might be due to the following reasons: (1) An observation depth of $18.7 \mathrm{GHz}$ and $36.5 \mathrm{GHz}$ passive microwave sensor was not exactly the same as the in-situ soil moisture measurement depth, which brought errors in discrimination of freeze/thaw states of the ground surface; (2) soil moisture increased with depth when the ground surface thawed, which resulted in a higher instability of soil emissivity; (3) most of the incorrect discriminations for the frozen ground surfaces were corrected by soil moisture information.

The distribution map of the number of days for the frozen soil over China, see Figure 10a-c, were in good agreement with the geocryological regionalization and classification map of China, see Figure 10d. Besides, the distribution map of the numbers of days for the frozen soil revealed much more detailed information compared with the map of the geocryological regionalization and classification of China.

\section{Conclusions}

An improved algorithm was proposed to identify the surface soil freeze/thaw states based on the original DIA in association with the AMSR-E and AMSR2 soil moisture products. By doing so, obviating the impact of soil moisture on the brightness temperature derived from passive microwave remote sensing was attempted. The local variance of soil moisture (LVSM) was introduced into the improved algorithm as an effective indicator for selecting a threshold to update and modify the original algorithm to better identify freeze/thaw states. The improved algorithm was validated with the in-situ observations from the Soil Moisture/Temperature Monitoring Network (SMTMN).

Based on our findings, the LVSM had evident seasonal variations which in fact represented soil freeze/thaw states. Our results showed a major improvement in the discrimination accuracy of the proposed algorithm compared with the original one. Additionally, the correct classification rate for the modified pixels was over $96 \%$. Integrating a surface soil freeze/thaw states discrimination algorithm with the AMSR-E and AMSR2 soil moisture product improved the classification performance reasonably and effectively. Overall, the methodology adopted and the results obtained in this study will have great implications for simulations of hydrological processes, and studies on cryosphere and global changes in cold regions.

Author Contributions: The first two authors (H.G. and W.Z.) contributed equally to this paper. H.G. and W.Z. conceived and designed the experiment; H.G. performed the experiments; H.C. processed and analyzed the data. H.G. wrote the paper manuscript. W.Z. revised the manuscript to improve the quality of the work. All authors have read the final manuscript.

Funding: This research was funded by the National Key R\&D Program of China grant number [No. 2016YFA0602302 and No. 2016YFB0502502].

Acknowledgments: The soil moisture and soil temperature datasets utilized in the present study was generously provided by Data Assimilation and Modeling Center for Tibetan Multi-spheres, Institute of Tibetan Plateau Research, Chinese Academy of Sciences. We would also wish to thank all the graduate students of Wanchang Zhang's group for their helpful comments in our weekly seminars.

Conflicts of Interest: The authors declare no conflict of interest.

\section{References}

1. Lachenbruch, A.H.; Marshall, B.V. Changing Climate: Geothermal Evidence from Permafrost in the Alaskan Arctic. Science 1986, 234, 689-696. [CrossRef] [PubMed]

2. Zhang, T.; Armstrong, R.L. Soil freeze/thaw cycles over snow-free land detected by passive microwave remote sensing. Geophys. Res. Lett. 2001, 28, 76-766. [CrossRef]

3. Smith, N.V.; Saatchi, S.S.; Randerson, J.T. Trends in high northern latitude soil freeze and thaw cycles from 1988 to 2002. J. Geophys. Res. Atmos. 2004, 109, D12101. [CrossRef]

4. Jin, M.S.; Mullens, T. A Study of the Relations between Soil Moisture, Soil Temperatures and Surface Temperatures Using ARM Observations and Offline CLM4 Simulations. Climate 2014, 2, 279-295. [CrossRef] 
5. Zuemdorfer, B.W.; England, A.W.; Dobson, M.C.; Ulaby, F.T. Mapping freeze/thaw boundaries with SMMR data. Agric. For. Meteorol. 1990, 52, 199-225. [CrossRef]

6. Judge, J.; Galantowicz, J.F.; England, A.W.; Dahl, P. Freeze/thaw classification for prairie soils using SSM/I radiobrightnesses. IEEE Trans. Geosci. Remote Sens. 1997, 35, 827-832. [CrossRef]

7. Goulden, M.L.; Wofsy, S.C.; Harden, J.W.; Trumbore, S.E.; Crill, P.M.; Gower, S.T.; Fries, T.; Daube, B.C.; Fan, S.M.; Sutton, D.J.; et al. Sensitivity of boreal forest carbon balance to soil thaw. Science 1998, 279, 214-217. [CrossRef] [PubMed]

8. Cheng, G.D.; Jin, H.J. Groundwater in the permafrost regions on the Qinghai-Tibet Plateau and it changes. Hydrogeol. Eng. Geol. 2013, 40,1-11.

9. Yao, T.D.; Qin, D.H.; Shen, Y.P.; Zhao, L.; Wang, N.L. Cryospheric changes and their impacts on regional water cycle and ecological conditions in the Qinghai-Tibetan Plateau. Chin. J. Nat. 2013, 35, 179-186.

10. Grody, N.C. Classification of snow cover and precipitation using the special sensor microwave imager. J. Geophys. Res. Atmos. 1991, 96, 7423-7435. [CrossRef]

11. Ulaby, F.T.; Kouyate, F.; Brisco, B.; Williams TH, L. Textural Information in SAR Images. IEEE Trans. Geosci. Remote Sens. 1986, 24, 235-245. [CrossRef]

12. England, A.W. Radio brightness of diurnally heated, freezing soil. IEEE Trans. Geosci. Remote Sens. 1990, 28, 464-476. [CrossRef]

13. Kimball, J.S.; Mcdonald, K.C.; Keyser, A.R.; Frolking, S.; Running, S.W. Application of the NASA Scatterometer (NSCAT) for Determining the Daily Frozen and Nonfrozen Landscape of Alaska. Remote Sens. Environ. 2001, 75, 113-126. [CrossRef]

14. Jin, R.; Xin, L.I. A Review on the Algorithms of Frozen/Thaw Boundary Detection by Using Passive Microwave Remote Sensing. Remote Sens. Technol. Appl. 2002, 17, 370-375.

15. Du, J.; Kimball, J.S.; Azarderakhsh, M.; Dunbar, R.S.; Moghaddam, M.; Mcdonald, K. Classification of Alaska Spring Thaw Characteristics Using Satellite L-Band Radar Remote Sensing. IEEE Trans. Geosci. Remote Sens. 2014, 53, 542-556. [CrossRef]

16. Mcdonald, K.C.; Kimball, J.S.; Njoku, E.; Zimmermann, R.; Zhao, M. Variability in springtime thaw in the terrestrial high latitudes: Monitoring a major control on the biospheric assimilation of atmospheric $\mathrm{CO}_{2}$ with space borne microwave remote sensing. Earth Interact. 2004, 8. [CrossRef]

17. Wismann, V. Monitoring of seasonal thawing in Siberia with ERS scatterometer data. IEEE Trans. Geosci. Remote Sens. 2000, 38, 1804-1809. [CrossRef]

18. Mcdonald, K.C.; Kimball, J.S. Estimation of surface freeze-thaw states using microwave sensors. In Encyclopedia of Hydrological Sciences; John Wiley \& Sons, Ltd.: Hoboken, NJ, USA, 2006.

19. Chai, L.N.; Zhang, L.X.; Zhang, Y.Y.; Hao, Z.G.; Zhang, L.M.; Zhao, J.P. Comparison of the classification accuracy of three soil freeze-thaw discrimination algorithms in China using SSMIS and AMSR-E passive microwave imagery. Int. J. Remote Sens. 2014, 35, 7631-7649. [CrossRef]

20. Han, M.L.; Yang, K.; Qin, J.; Jin, R.; Ma, Y.M.; Wen, J.; Cheng, Y.Y.; Zhao, L.; Zhu, L.; Tang, W.J. An Algorithm Based on the Standard Deviation of Passive Microwave Brightness Temperatures for Monitoring Soil Surface Freeze/Thaw State on the Tibetan Plateau. IEEE Trans. Geosci. Remote Sens. 2015, 53, 2775-2783. [CrossRef]

21. Zuemdorfer, B.; England, A.W. Radio brightness decision criteria for freeze/thaw boundaries. IEEE Trans. Geosci. Remote Sens. 1992, 30, 89-102. [CrossRef]

22. Wegmüller, U. The effect of freezing and thawing on the microwave signatures of bare soil. Remote Sens. Environ. 1990, 33, 123-135. [CrossRef]

23. Zuemdorfer, B.; England, A.W.; Wakefield, G.H. The radio brightness of freezing terrain. In Proceedings of the 12th Canadian Symposium on Remote Sensing International Conference, Vancouver, BC, Canada, 10-14 July 1989.

24. Cao, M.S.; Zhang, T.J. Monitoring terrain soil freeze/ thaw condition on Qinghai plateau in spring and autumn using microwave remote sensing. J. Remote Sens. 1997, 1, 139-144.

25. Zhang, T.; Jin, R.; Gao, F. Overview of the Satellite Remote Sensing of Frozen Ground: Passive Microwave Sensors. Adv. Earth Sci. 2009, 24, 1073-1083.

26. Jin, R.; Li, X.; Tao, C. A decision tree algorithm for surface soil freeze/thaw classification over China using SSM/I brightness temperature. Remote Sens. Environ. 2009, 113, 2651-2660. [CrossRef]

27. Zhao, T.J.; Zhang, L.X.; Jiang, L.M.; Zhao, S.J.; Chai, L.N.; Jin, R. A new soil freeze/thaw discriminant algorithm using AMSR-E passive microwave imagery. Hydrol. Processes 2011, 25, 1704-1716. [CrossRef] 
28. Kou, X.K.; Jiang, L.M.; Yan, S.; Zhao, T.J.; Lu, H.; Cui, H.Z. Detection of land surface freeze-thaw status on the Tibetan Plateau using passive microwave and thermal infrared remote sensing data. Remote Sens. Environ. 2017, 199, 291-301. [CrossRef]

29. Kim, Y.; Kimball, J.S.; Mcdonald, K.C.; Glassy, J. Developing a Global Data Record of Daily Landscape Freeze/Thaw Status Using Satellite Passive Microwave Remote Sensing. IEEE Trans. Geosci. Remote Sens. 2011, 49, 949-960. [CrossRef]

30. Park, S.E.; Bartsch, A.; Sabel, D.O.; Wagner, W.; Naeimi, V.; Yamaguchi, Y. Monitoring freeze/thaw cycles using ENVISAT ASAR Global Mode. Remote Sens. Environ. 2011, 115, 3457-3467. [CrossRef]

31. Rautiainen, K.; Lemmetyinen, J.; Schwank, M.; Kontu, A.; Menard, C.B.; Matzler, C.; Drusch, M.; Wiesmann, A.; Ikonen, J.; Pulliainen, J. Detection of soil freezing from L-band passive microwave observations. Remote Sens. Environ. 2014, 147, 206-218. [CrossRef]

32. Roy, A.; Royer, A.; Derksen, C.; Brucker, L.; Langlois, A.; Mialon, A.; Kerr, Y.H. Evaluation of Spaceborne L-Band Radiometer Measurements for Terrestrial Freeze/Thaw Retrievals in Canada. IEEE J. Sel. Top. Appl. Earth Obs. Remote Sens. 2015, 8, 4442-4459. [CrossRef]

33. Rautiainen, K.; Parkkinen, T.; Lemmetyinen, J.; Schwank, M.; Wiesmann, A.; Ikonen, J.; Derksen, C.; Davydov, S.; Davydova, A.; Boike, J.; et al. SMOS prototype algorithm for detecting autumn soil freezing. Remote Sens. Environ. 2016, 180. [CrossRef]

34. Brocca, L.; Hasenauer, S.; Lacava, T.; Melone, F.; Moramarco, T.; Wagner, W.; Dorigo, W.; Matgen, P.; Martínez-Fernández, J.; Llorens, P.; et al. Soil moisture estimation through ASCAT and AMSR-E sensors: An intercomparison and validation study across Europe. Remote Sens. Environ. 2011, 115, 3390-3408. [CrossRef]

35. Albergel, C.; Zakharova, E.; Calvet, J.C.; Zribi, M. A first assessment of the SMOS data in southwestern France using in situ, airborne and model soil moisture estimates. Remote Sens. Environ. 2011, 115, 2718-2728. [CrossRef]

36. Yaari, A.; Wigneron, J.P.; Ducharne, A.; Kerrc, Y.; Wagnere, W.; Reichled, R.; Lannoyd, G.D.; Bitarc, A.A.; Dorigoe, W.; Parrensc, M.; et al. Compared performances of microwave passive soil moisture retrievals (SMOS) and active soil moisture retrievals (ASCAT) using land surface model estimates (MERRA-LAND). In Proceedings of the International Geoscience and Remote Sensing Symposium (IGARSS), Quebec City, QC, Canada, 13-18 July 2014.

37. Zhong, A.F.; Wang, A.Q.; Li, J.W.; Xu, T.B.; Meng, D.; Ke, Y.H.; Li, X.J.; Chen, Y. Downscaling of passive microwave soil moisture retrievals based on spectral analysis. Int. J. Remote Sens. 2018, 39, 50-67. [CrossRef]

38. Gonzalez, R.C.; Woods, R.E. Digital Image Process; Addison-Wesley Longman Publishing Co., Inc.: Boston, MA, USA, 1992.

39. Ajafernandez, S.; Estepar, R.S.; Alberolalopez, C.; Westin, C. Image Quality Assessment based on Local Variance. In Proceedings of the Annual International Conference of the IEEE Engineering in Medicine and Biology Society, New York City, NY, USA, 30 August-3 September 2006.

40. Wang, Y.Q.; Liu, W.Y.; Yong, W. Image quality assessment based on local variance and structure similarity. J. Optoelectron. Laser 2008, 19, 1546-1553.

41. Yang, K.; Qin, J.; Zhao, L.; Cheng, Y.Y.; Tang, W.J.; Han, M.L.; Zhu, L.; Chen, Z.Q.; Lv, N.; Ding, B.H.; et al. A Multi-Scale Soil Moisture and Freeze-Thaw Monitoring Network on the Third Pole. Bull. Am. Meteorol. Soc. 2013, 94, 1907-1916. [CrossRef]

42. Qin, J.; Yang, K.; Lu, N.; Cheng, Y.Y.; Zhao, L.; Han, M.L. Spatial upscaling of in-situ soil moisture measurements based on MODIS-derived apparent thermal inertia. Remote Sens. Environ. 2013, 138, 1-9. [CrossRef]

43. Njoku, E.G.; Chan, T.; Crosson, W.; Limaye, A. Evaluation of the AMSR-E Data Calibration Over Land. Ital. J. Remote Sens. 2004, 29, 19-37.

44. Cho, E.; Su, C.H.; Ryu, D.; Choi, M. Does AMSR2 produce better soil moisture retrievals than AMSR-E over Australia? Remote Sens. Environ. 2017, 188, 95-105. [CrossRef]

45. Njoku, E.G.; Jackson, T.J.; Lakshmi, V.; Chan, T.K.; Nghiem, S.V. Soil moisture retrieval from AMSR-E. IEEE Trans. Geosci. Remote Sens. 2003, 41, 215-229. [CrossRef]

46. Yang, X.H.; Zaxiyangzong; Zhouga; Bianbaciren. Relation of vegetation coverage to meteorological conditions in the Naqu area of Tibet. Acta Pratacult. Sin. 2008, 17, 102-109. 
47. Fujii, H.; Koike, T.; Imaoka, K. Improvement of the AMSR-E algorithm for soil moisture estimation by introducing a fractional vegetation coverage dataset derived from MODIS data. J. Remote Sens. Soc. Japan 2009, 29, 282-292.

48. Zeng, J.Y.; Li, Z.; Chen, Q.; Bi, H.Y.; Qiu, J.X.; Zou, P.F. Evaluation of remotely sensed and reanalysis soil moisture products over the Tibetan Plateau using in-situ observations. Remote Sens. Environ. 2015, 163, 91-110. [CrossRef]

49. Seneviratne, S.I.; Corti, T.; Davin, E.L.; Hirschi, M.; Jaeger, E.B.; Lehner, L.; Orlowsky, B.; Teuling, A. Investigating soil moisture-climate interactions in a changing climate: A review. Earth Sci. Rev. 2010, 99, 125-161. [CrossRef]

50. Zhao, G.; Fan, T.L.; Li, S.Z.; Zhang, J.J.; Wang, Y.; Dang, Y.; Wang, L. Soil moisture dynamics of apple orchard in Loess Plateau dryland. J. Appl. Ecol. 2015, 26, 1199-1204.

51. Malbéteau, Y.; Merlin, O.; Molero, B.; Rüdiger, C.; Bacon, S. DisPATCh as a tool to evaluate coarse-scale remotely sensed soil moisture using localized in situ measurements: Application to SMOS and AMSR-E data in Southeastern Australia. Int. J. Appl. Earth Obs. Geoinf. 2016, 45, 221-234. [CrossRef]

52. Aja-Fernández, S.; Estépar, R.S.; Alberola-López, C.; Westin, C.F. Image Quality Assessment based on Local Variance. In Proceedings of the 28th IEEE EMBS Annual International Conference, New York City, NY, USA, 30 August-3 September 2006.

53. Zhou, Y.W.; Guo, D.X.; Qiu, G.Q.; Cheng, G.D.; Li, S.D. Geocryology in China Beijing; Science Press in Chinese: Beijing, China, 2000.

(C) 2018 by the authors. Licensee MDPI, Basel, Switzerland. This article is an open access article distributed under the terms and conditions of the Creative Commons Attribution (CC BY) license (http://creativecommons.org/licenses/by/4.0/). 